\title{
Thalidomide and its analogues: A review of the potential for immunomodulation of fibrosis diseases and opthalmopathy (Review)
}

\author{
TING LIU* , FENG GUO* ${ }^{*}$ XIAOMIN ZHU, XIANGGE HE and LIN XIE \\ Department of Ophthalmology, Daping Hospital and Research Institute of Surgery, \\ The Third Military Medical University, People's Liberation Army, Chongqing 400042, P.R. China
}

Received February 2, 2016; Accepted February 14, 2017

DOI: $10.3892 /$ etm.2017.5209

\begin{abstract}
The US Food and Drug Administration approved thalidomide and its analogues for the treatment of erythema nodosum leprosum, in spite of the notoriety of reports of severe birth defects in the middle of the last century. As immunomodulatory drugs, thalidomide and its analogues have been used to effectively treat various diseases. In the present review, preclinical data about the effects of thalidomide and its analogues on the immune system are integrated, including the effects of cytokines on transdifferentiation, the anti-inflammatory effect, immune cell function regulation and angiogenesis. The present review also investigates the latest developments of thalidomide as a therapeutic option for the treatment of idiopathic pulmonary fibrosis, skin fibrosis, and ophthalmopathies.
\end{abstract}

\section{Contents}

1. Introduction

2. Biological effects of thalidomide and its analogues

3. Roles of IMiDs in fibrosis disease and ophthalmology

4. Adverse effects

5. Conclusion

Correspondence to: Professor Lin Xie, Department of Ophthalmology, Daping Hospital and Research Institute of Surgery, The Third Military Medical University, People's Liberation Army, 10 Changjiang Brach Road, Chongqing 400042, P.R. China E-mail: xielin_66@163.com

${ }^{*}$ Contributed equally

Key words: thalidomide, immunomodulatory drugs, idiopathic pulmonary fibrosis, skin fibrosis, opthalmopathies

\section{Introduction}

Thalidomide was first synthesized from the glutamic acid derivative $\alpha$-phthaloyliso-glutamine in Germany in 1954 and was mistakenly assumed to be safe due to its structural resemblance to barbiturates (1). Thalidomide received considerable attention due to reports of severe birth defects in the infants of women who had been prescribed the drug as an anti-emetic $(2,3)$. Following these reports, it was withdrawn from the European market for $>40$ years (3). Thalidomide was approved by the US Food and Drug Administration (FDA) in 1998 due to its anti-inflammatory effect in the treatment of erythema nodosum leprosum (ENL), a painful inflammatory complication of leprosy (4). This led to its unrecognized pharmacological properties being investigated as a potential immunomodulatory, anti-inflammatory and anti-angiogenic agent for the treatment of other serious diseases $(3,4)$.

Currently, thalidomide and its analogues (CC5013 and CC-4047) are being used as novel immunomodulatory drugs (IMiDs) for the treatment of various diseases, including lupus erythematosis, Behcet's disease, inflammatory bowel disease, solid tumors, hematologic malignancies, and heart failure (4-7). CC5013 (lenalidomide, Revlimid) and CC4017 (ACTIMID, pomalidomide) were initially developed as inhibitors of tumor necrosis factor- $\alpha$ (TNF- $\alpha$ ) (5). Following minor structural modifications of thalidomide, CC5013 and CC4017 are effective regulators of the immune reaction and cytokine response with none of the adverse effects of thalidomide (6).

At present, the novel analogues of thalidomide are in phase III clinical trials and are showing promising results (7). The present review summarizes the biological effects of thalidomide and its IMiD analogues on cytokine elaboration, inflammation, immune cell function regulation and angiogenesis (Table I). Additionally, previous studies of thalidomide and its analogues used for the treatment of fibrotic diseases such as pulmonary fibrosis, skin fibrosis, and ophthalmopathies are presented (Table II).

\section{Biological effects of thalidomide and its analogues}

Cytokine elaboration and anti-inflammatory effects on TNF- $\alpha$. As IMiDs, thalidomide and its analogues have clinically 
relevant effects on cytokine elaboration (5). In patients with ENL, a Mycobacterial infection complication, treatment with thalidomide reduced the lipopolysaccharide (LPS)-induced TNF- $\alpha$ secretion by monocytes or macrophages through accelerating TNF- $\alpha$ mRNA degradation and inhibiting nuclear factor $\kappa \mathrm{B}(\mathrm{NF}-\kappa \mathrm{B})$ activation (Fig. 1) (8-10). Thalidomide has also been demonstrated to exert an effect on other inflammatory conditions that present with TNF- $\alpha$ upregulation, such as rheumatoid arthritis, Crohn's disease, tuberculosis and cancer (11-14). Furthermore, in the setting of spinal cord ischemia, thalidomide pretreatment has been demonstrated to reduce early phase ischemia/reperfusion injury of the spinal cord in rabbits via reducing TNF- $\alpha$ production (15). CC5013 and CC4017 are considered to be more effective TNF- $\alpha$ antagonists than thalidomide, and their inhibiting effect on TNF- $\alpha$ production has been reported as being as much as 100-50,000 times higher $(16,17)$.

Cytokine elaboration and anti-inflammatory effects on transforming growth factor- $\beta$ (TGF- $\beta$ ) and others. The TGF- $\beta$ superfamily consists of various proteins that regulate numerous physiological processes, including embryogenesis, immunity, carcinogenesis, cell proliferation and migration, wound healing, inflammation and fibrosis, among others (18). Smad and non-canonical pathways are the two primary signaling pathways in the TGF- $\beta$ system (18). In Smad-related pathways, complex interactions between intracellular diverse molecules associated with the downstream TGF- $\beta$ signaling cascade result in fibrosis, such as phosphorylation or direct interaction with Smad (19). Non-canonical signaling pathways include the mitogen-activated protein kinase (MAPK), Rho-like GTPase and phosphatidylinositol-3-kinase/protein kinase B (AKT) pathways (18). Extracellular signal-regulated kinase1/2 (ERK1/2), c-Jun- $\mathrm{NH}_{2}$-terminal kinase, and p38 MAPK signaling pathways are well-established non-canonical pathways of TGF- $\beta$ signaling (20). In a mouse model of bleomycin-induced lung fibrosis, Choe et al (21) demonstrated that thalidomide administration significantly inhibited TGF- $\beta 1$ mRNA expression in a dose-dependent manner following the administration of interleukin (IL)-6 and IL-6R, and they concluded that the anti-fibrotic effects of thalidomide may be associated with the inhibition of TGF- $\beta 1$-mediated non-Smad ERK1/2 signaling pathways. Furthermore, Liang et al (22) found that thalidomide treatment inhibited fibronectin production in normal and keloid fibroblasts stimulated by TGF- $\beta 1$, and enhanced the phosphorylation of MAPKs and Smad 2/3. They also revealed that inhibited $\mathrm{p} 38 / \mathrm{Smad} 3$ pathways were involved in the anti-fibrotic mechanisms of thalidomide (Fig. 1) (22). Other than TNF- $\alpha$ and TGF- $\beta$, the expression levels of other cytokines including IL-1 $\beta$, IL-6, and granulocyte macrophage-colony stimulating factor were also suppressed by thalidomide in LPS-induced peripheral blood monocytes, whereas IL-10 was stimulated $(23,24)$.

Anti-inflammatory effect. Li et al (25) demonstrated that the derivatives of thalidomide were able to downregulate CCAAT-/enhancer-binding protein- $\beta$ (C/EBP- $\beta$ )-related cell proliferation and inhibit 5'-cap-dependent translation of $\mathrm{C} / \mathrm{EBP}$, both of which are associated with eukaryotic translation initiation factor 4E (eIF4E) (25). Cyclooxygenase (COX)-2, a key regulator in arachidonic acid metabolism and prostaglandin generation, is an important anti-inflammatory target (26).
LPS-induced COX-2 expression is transcriptionally regulated by $\mathrm{C} / \mathrm{EBP}$ isoforms (27); therefore, IMiDs may be directly involved in the eIF4E-dependent regulation of COX-2 expression. Furthermore, selective upregulation of COX-2 expression has been observed in myeloma cells, and COX-2 inhibition in these cells may eliminate the protective effects of bone marrow stromal cells on myeloma following chemotherapy (28). A phase II clinical trial found that selective inhibition of COX-2 by thalidomide has an effect in multiple myeloma (MM) (29), which suggests that the anti-inflammatory effect of IMiDs may be relevant to COX-2 inhibition.

T cell and natural killer (NK) cell functions. Correlative preclinical studies have suggested that IMiDs act as co-stimulators on the release of IL-2 and interferon (IFN)- $\gamma$ from T lymphocytes undergoing CD3 ligation or mitogenic stimulation, or in response to dendritic cells presented with antigens (30). This may result in $\mathrm{T}$ cell proliferation, $\mathrm{T}$ helper cells skewing and augmentation of cytotoxic effector functions (31). Co-stimulation of $\mathrm{T}$ cells by lenalidomide is only partially blocked by the negative co-stimulator cytotoxic $\mathrm{T}$ lymphocyte-associated antigen-4 (CTLA-4) in the B7/CD28 co-stimulatory axis (32). Furthermore, tyrosine phosphorylation of CD28 induced by lenalidomide was able to facilitate the recruitment and activation of upstream molecules in multiple intracellular signaling pathways, including phosphatidylinositol-3-kinase (PI3K) and $\mathrm{NF}-\kappa \mathrm{B}$ (33). As CD28 and IMiDs have no kinase activity, other signaling proteins such as protein kinase $\mathrm{C}$ (PKC) may be involved in the indirect mechanism underlying CD28 phosphorylation $(34,35)$. Payvandi et al (35) demonstrated that IMiDs increased IL-2 production in stimulated T cells via enhancing PKC- $\theta$ activation and DNA-binding activity of activated protein-1 (AP-1). In addition to conventional $\mathrm{T}$ cells, regulatory $\mathrm{T}$ cells (Tregs) are a group of immunosuppressive $\mathrm{T}$ cells that function in self-tolerance and the immune response (36). Inhibition of Tregs by lenalidomide (Revlimid; CC-5013) and pomalidomide (CC-4047) via decreasing the expression of forkhead box P3 (FoxP3) was observed in a preclinical study (32). Furthermore, Gandhi et al (37) reported that the lenalidomide (or pomalidomide)-binding protein cereblon was able to cause the Ikaros and Aiolos to interact with the E3 ubiquitin ligase CUL4-RBX1-DDB1-CRBN (known as CRL4CRBN), resulting in their ubiquitination, proteasome degradation and $\mathrm{T}$ cell activation.

IMiDs also exert their immunomodulatory effects by modulating the number and function of NK cells. Zhu et al (38) reported that CC-5013 and CC-4047 increased the population of NK and NKT cells in the setting of hematological malignancy (38). Furthermore, Wu et al (39) demonstrated that lenalidomide was able to enhance the NK cell-mediated antibody-dependent cellular cytotoxicity (ADCC) effect on rituximab-treated CD20+ tumor cells (39). It was also revealed that enhanced NK cell Fc-gamma receptor signaling was associated with enhanced phosphorylation of ERK (39).

Anti-angiogenic properties. Neovascularization, a well-known consequence of the inflammatory response (31), provides an insight into the inherent connection between inflammatory cytokines and angiogenic pathway. Yaccoby et al (40) demonstrated that peritoneal injection with thalidomide inhibited 
Table I. Biological effects of thalidomide and its analogues.

Biological effect

Cytokine elaboration and anti-inflammatory effect

T cell and natural killer cell function regulation

Anti-angiogenic properties
Implementation

Decreased or increased levels of TNF- $\alpha$, TGF- $\beta$, IL-1 $\beta$, IL-6 and granulocyte macrophage colony stimulating factor

T cell proliferation, T helper cells skewing, augmentation of the cytotoxic effector, regulatory $\mathrm{T}$ cell inhibition and NK cell proliferation and function

Downregulation of adhesion molecules (such as intercellular adhesion molecule-1), increase in PDGF-B expression; decreased paracrine production of pro-angiogenic VEGF and IL-6

TNF, tumor necrosis factor; TGF, transforming growth factor; IL, interleukin; NK, natural killer; PDGF, platelet-derived growth factor; VEGF, vascular endothelial growth factor.

Table II. Applications of thalidomide and its analogues in pulmonary fibrosis, skin fibrosis, and ophthalmopathies.

Disease

Mechanisms

\section{Skin fibrosis}

Idiopathic pulmonary fibrosis

Ophthalmopathy
Induces immune stimulation resulting in IL-6 production and fibrosis synthesis via TGF- $\beta$ /phospho-Smad $2 / 3$ pathway

Exerts an inhibitory effect on the cytokine profile from alveolar macrophage, modulates TGF- $\beta 1$-induced ERK1/2 signaling pathway, downregulates BMP signaling, increases Wnt and Akt activities and apoptosis resistance

Regulates neovascularization through VEGF and TNF- $\alpha$ and has anti-inflammatory effects

IL, interleukin; TGF, transforming growth factor; ERK, extracellular signaling-related kinase; BMP, bone morphogenetic protein; Akt, protein kinase B; VEGF, vascular endothelial growth factor; TNF, tumor necrosis factor.

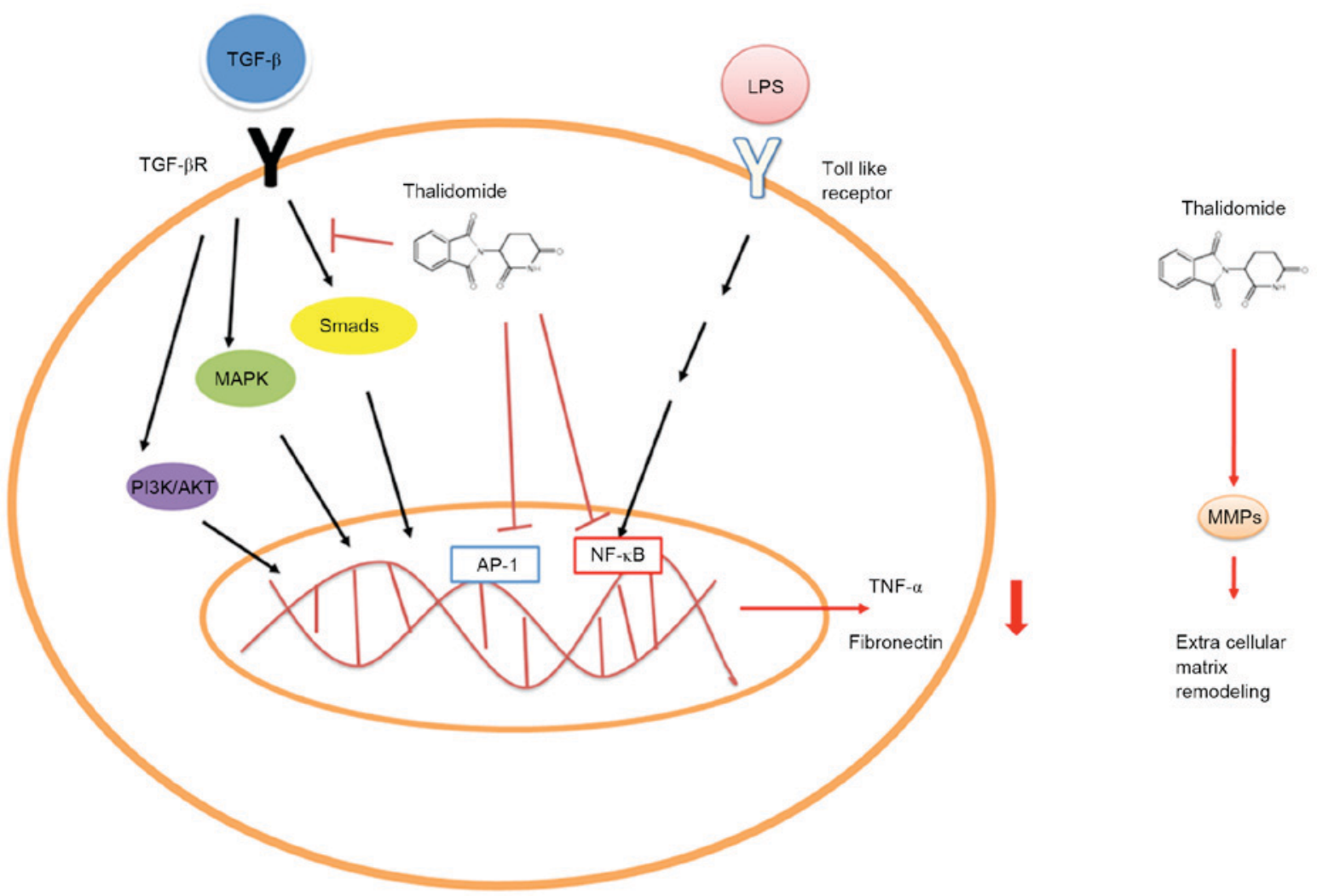

Figure 1. Regulation mechanism by which thalidomide affects cytokine elaboration. Thalidomide affects the production of fibronectin and TNF- $\alpha$ via regulating TGF- $\beta$ signaling and NF- $\mathrm{\kappa B}$ transcription, respectively, and regulates the extra cellular matrix remodeling via MMPs. TNF, tumor necrosis factor; TGF, transforming growth factor; NF, nuclear factor; MMP, metal matrix protein; LPS, lipopolysaccharide; MAPK, mitogen-activated protein kinase; AKT, protein kinase B; AP, activated protein. 
myeloma growth in severe combined immunodeficiency-human (SCID-hu) mice implanted with fetal human liver fragments. Reduced micro vessel density was observed in myeloma xenografts of thalidomide-treated fetal liver-bearing mice compared with non-fetal liver implanted hosts. They concluded that thalidomide treatment is strongly correlated with decreased micro vessel density; however, they did not determine whether the reduction in microvascular density is one of the main results of thalidomide antiangiogenic activity or if it was a secondary process to reduce tumor burden. In a rat model of hepatic cirrhosis, Lv et al (41) reported that thalidomide was able to downregulate NF- $\mathrm{NB}$-induced expression of adhesion molecules (such as intercellular adhesion molecule-1) and activation of hepatic stellate cells via inhibiting the degradation of $\mathrm{I} \kappa \mathrm{B}$ to reverse the disease. In the setting of hereditary hemorrhagic telangiectasia, thalidomide treatment stimulated mural cell coverage and restored vessel wall defects via increasing the platelet-derived growth factor-B expression in endothelial cells and stimulating mural cell activation (42).

Despite the putative role of metabolism in the IMiD-mediated inhibition of vascularization, thalidomide and its analogues have been demonstrated to have an antagonistic effect on several key angiogenesis regulators (31). IMiDs decrease the paracrine production of pro-angiogenic vascular endothelial growth factor (VEGF) and IL-6 at the bone marrow stroma and MM cell levels (43). Furthermore, thalidomide suppresses the expression of VEGF receptors in human umbilical vein endothelial cells (HUVECs) via activating sphingolipid signaling (44). Reduced cell migration responses to basic fibroblast growth factor (bFGF) and VEGF due to downregulation of AKT phosphorylation was observed in lenalidomide treated HUVEC cells $(45,46)$. The suppression of pro-angiogenic factors such as IL-6, TNF- $\alpha$, VEGF, NF- $\kappa \mathrm{B}$ and prostaglandin synthesis by thalidomide and its analogues may indirectly downregulate angiogenesis in vivo.

\section{Role of IMiDs in fibrosis disease and ophthalmopathy}

Skin fibrosis. Skin fibrosis, characterized by physiological tissue architecture damage, is a major hallmark of systemic sclerosis (SSc) and causes high morbidity among patients (47). As efficient immunomodulators, thalidomide and its analogues have been suggested as a treatment for treat skin fibrosis. Oliver et al (48) reported that thalidomide improved the clinical manifestations of patients with SSc by stimulating the immune response. In a preclinical study by Weingärtner et al (49), the newest second generation IMiD, pomalidomide, was demonstrated to prevent spontaneous hypodermal fibrosis and induce its regression in bleomycin-induced dermal fibrosis mice and tight-skin mice. An international, multicenter, controlled phase II clinical trial (gov ID: NCT01559129) was initiated to evaluate pomalidomide as a treatment for patients with SSc (49). Most recently, Ingen-Housz-Oro et al (50) reported that two cases of Ig4-related skin diseases were successfully treated with thalidomide, and they concluded that interactions between Tregs and mast cells may result in IL- 6 production and fibrosis via the TGF- $\beta$ /phospho-Smad 2/3 pathway.

Idiopathic pulmonary fibrosis. Idiopathic pulmonary fibrosis (IPF), characterized by epithelial injury and fibroblast proliferation in the lungs, is a chronic progressive lung disease with a prevalence of 16-18 in 10,000 and a five-year mortality rate over $50 \%$ (51). Inflammatory cytokines and angiogenesis serve critical roles in the pathological progression of IPF. It has been reported that thalidomide exerts an inhibitory effect on the cytokine profile in patients with IPF $(52,53)$. Tabata et al $(54)$ reported that thalidomide pretreatment prevented the development of bleomycin-induced pulmonary fibrosis (PF) in a mouse model. Choe et al (21) further confirmed that the TGF- $\beta 1$-induced activation of the ERK1/2 signaling pathway accounted for the anti-fibrotic effect of thalidomide in a bleomycin-induced PF model. Knobloch et al (55) reported that the underlying mechanisms of this effect included downregulation of bone morphogenetic protein signaling, an increase in the activity of Wnt and Akt and enhanced apoptosis resistance. In a clinical trial conducted by Horton et al (56), thalidomide treatment was demonstrated to improve coughing and respiratory symptoms, as well as quality of life, in patients with IPF.

Ophthalmopathy. D'Amato, an ophthalmologist, first considered thalidomide when searching for treatments for two diseases that cause blindness, macular degeneration and diabetic retinopathy (57). Both diseases result in excessive blood vessel growth, which burst in the eye and destroy the patient's vision (57). It was reported that thalidomide was an effective anti-angiogenesis inhibitor in the setting of bFGF-induced angiogenesis in a rabbit cornea micropocket assay (58), and Kruse et al (59) suggested that thalidomide inhibited VEGF-induced corneal angiogenesis in New Zealand white rabbits. Ribeiro et al (60) used a novel thalidomide hybrid (LASSBio-596) to treat inflammatory corneal angiogenesis in rabbits, and reported that it had an inhibitory effect. In an alkali burn model of corneal angiogenesis, Abbas et al (61) demonstrated that thalidomide was able to prevent corneal angiogenesis and prolong graft survival (as measured by graft clarity in donor corneas in eyes). Furthermore, Lee and Chung (62) has reported a similar inhibitory effect of thalidomide on corneal neovascularization in a silk suture-induced rabbit model, though to be achieved via regulating VEGF and TNF- $\alpha$ expression levels. However, Srinivasan et al (63) reported the case of a patient who presented with bilateral symmetrical corneal endothelial changes, which was found to be associated with thalidomide toxicity. Huang et al (64) reported a 45-year woman with gradual visual decline due to crystalline materials in the cornea. The patient was treated with thalidomide and, at a seven-year follow up, her vision was stable and the corneal crystalline deposits had decreased and migrated.

In addition to functioning as an anti-angiogenesis inhibitor, thalidomide may also used as anti-inflammatory agent in ophthalmopathy. In a rat model of endotoxin-induced uveitis (EIU), Guex-Crosier et al (65) revealed that high-dose thalidomide had an effective anti-inflammatory effect, whereas lower doses were insufficient to reduce inflammation. Rodrigues et al (66) further investigated the preventive and therapeutic anti-inflammatory effects of systemic and topical thalidomide in EIU rats. Parentin et al (67) reported that thalidomide was an effective treatment for bilateral chronic idiopathic anterior uveitis in a three-year-old child; however, Ip et al (68) reported a case in which thalidomide was not able to prevent the recurrence of a choroidal neovascular membrane (CNM). Using a mouse model, Rabinowitz et al (69) also 
demonstrated that thalidomide had no significant effect on neovascularization in oxygen-induced retinopathy.

It has been reported that exposure to thalidomide has negative side effects on the eyes. For example, anophthalmia and microphthalmia (the absence of an eye and the presence of a small eye within the orbit, respectively) are both disease caused by exposure to thalidomide (70). There have been no large sample clinical trials investigating the effect of thalidomide on ophthalmopathies, and so the application of thalidomide in the patients with certain types of eye diseases remains controversial.

\section{Adverse effects}

Birth defects such as phocomelia and deformities of the ears, eyes, and gastrointestinal tract caused by thalidomide have been widely reported (3). A novel generation IMiD, slenalidomide, caused thalidomide-like fetal malformations in monkeys (71), but not in rabbits (72). Pomalidomide, another thalidomide analogue approved by the FDA, was teratogenic in both rats and rabbits when administered during the period of organogenesis (73). In rabbits, pomalidomide has been found to cause cardiac malformations and anomalies in the limbs and digits. Fetal abnormalities observed in rats included fetal visceral defects and abnormalities in vertebral elements (74).

Pomalidomide has been evaluated in a number of clinical trials involving patients with relapsed MM and myelofibrosis (75). The primary complication reported previously was neutropenia, followed by anemia and thrombocytopenia $(76,77)$. Although thrombo-prophylaxis (daily low-dose aspirin in the majority of cases) was applied, the frequency of venous thromboembolism was similar to that observed with other IMiDs. In a Mayo Clinic phase II trial (NCT00558896) (78), peripheral neuropathy was reported in $60(17.3 \%)$ patients during the treatment period. In a phase II trial of patients with myelofibrosis, the major side effects included fatigue/asthenia, thrombocytopenia, pneumonia/sepsis and anemia (79).

Lenalidomide has also been assessed in two phase III registration clinical trials (MM-009 and MM-010) (80,81). Despite being an immunomodulatory agent, the toxicity profile of lenalidomide is different from that of thalidomide. In clinical practice, lenalidomide is typically used in combination with dexamethasone and the most frequent toxic events of this combination therapy include myelosuppression (neutropenia, thrombocytopenia, and less typically, anemia), infections, and thrombosis (particularly when combined with high dose of dexamethasone and with antithrombotic prophylaxis) (82).

\section{Conclusion}

Thalidomide and its analogues have been shown to have pleotropic immunomodulatory and anti-angiogenesis effects. In addition to its conventional use to treat patients with solid tumors or hematological malignancies, thalidomide also exhibits therapeutic effects as a treatment for skin fibrosis, idiopathic pulmonary fibrosis and ophthalmopathies. The molecular mechanisms underlying IMiD activity are likely to be both divergent and complementary across these distinct diseases. The complexity of IMiD biology is highlighted by the combined ability to modulate multiple targets from the epigenetic to post-translational protein modulations, systemic cytokine networks and immune cell function regulation. However, the adverse effects of thalidomide treatment, including birth deformity, neutropenia, anemia, thrombocytopenia, and even DVT reduces the safety of thalidomide treatment. It is hoped that identification of novel drug targets may allow for therapeutic manipulation of novel non-IMiD pharmaceuticals to elicit the clinical benefits without the adverse side effects in the future.

\section{Acknowledgements}

The present study was supported by the National Natural Science Foundation of China (grant nos. 81170852 and 81470629) and the Natural Science Foundation of Chongqing (grant no. CSTC2013jjB10030).

\section{References}

1. Schulz M: Dark remedy: the impact of thalidomide and its revival as a vital medicine. BMJ 322: 1608, 2001.

2. Han ZX, Xu J, Wang HM, Ma J, Sun X and Du XP: Antiemetic role of thalidomide in a rat model of cisplatin-induced emesis. Cell Biochem Biophys 70: 361-365, 2014.

3. Vargesson N: Thalidomide-induced teratogenesis: History and mechanisms. Birth Defects Res C Embryo Today 105: 140-156, 2015.

4. Teo S, Resztak KE, Scheffler MA, Kook KA, Zeldis JB, Stirling DI and Thomas SD: Thalidomide in the treatment of leprosy. Microbes Infect 4: 1193-1202, 2002.

5. Lopez-Millan B, Diaz de la Guardia R, Roca-Ho H, García-Herrero CM, Lavoie JR, Rosu-Myles M, Gonzalez-Rey E, O'Valle F, Criado G, Delgado M and Menendez P: Therapeutic effect of the immunomodulatory drug lenalidomide, but not pomalidomide, in experimental models of rheumatoid arthritis and inflammatory bowel disease. Exp Mol Med 49: e290, 2017.

6. Bartlett JB, Dredge K and Dalgleish AG: The evolution of thalidomide and its IMiD derivatives as anticancer agents. Nat Rev Cancer 4: 314-322, 2004.

7. Galustian C, Meyer B, Labarthe MC, Dredge K, Klaschka D, Henry J, Todryk S, Chen R, Muller G, Stirling D, et al: The anti-cancer agents lenalidomide and pomalidomide inhibit the proliferation and function of $\mathrm{T}$ regulatory cells. Cancer Immunol Immunother 58: 1033-1045, 2009.

8. Moreira AL, Sampaio EP, Zmuidzinas A, Frindt P, Smith KA and Kaplan G: Thalidomide exerts its inhibitory action on tumor necrosis factor alpha by enhancing mRNA degradation. J Exp Med 177: 1675-1680, 1993.

9. Keifer JA, Guttridge DC, Ashburner BP and Baldwin AS Jr: Inhibition of NF-kappa B activity by thalidomide through suppression of Ikappa B kinase activity. J Biol Chem 276: 22382-22387, 2001.

10. Sampaio EP, Kaplan G, Miranda A, Nery JA, Miguel CP, Viana SM and Sarno EN: The influence of thalidomide on the clinical and immunologic manifestation of erythema nodosum leprosum. J Infect Dis 168: 408-414, 1993.

11. Zuo XX, Gong YH, Zhou YO, Luo H and Xiao XZ: The plasmic translocation and release of high mobility group box chromosomal protein 1 in peripheral blood monocytes of patients with rheumatoid arthritis and the effect of thalidomide. Zhonghua Nei Ke Za Zhi 47: 374-377, 2008.

12. Barkin JA, Schonfeld WB and Deshpande AR: Successful use of thalidomide for refractory esophageal Crohn's disease. Am J Gastroenterol 108: 855-857, 2013.

13. Fourcade C, Mauboussin JM, Lechiche C, Lavigne JP and Sotto A: Thalidomide in the treatment of immune reconstitution inflammatory syndrome in HIV patients with neurological tuberculosis. AIDS Patient Care STDS 28: 567-569, 2014.

14. Beedie SL, Peer CJ, Pisle S, Gardner ER, Mahony C, Barnett S, Ambrozak A, Gütschow $\mathrm{M}$, Chau $\mathrm{CH}$, Vargesson $\mathrm{N}$ and Figg WD: Anti-Cancer properties of a novel class of tetrafluorinated thalidomide analogs. Mol Cancer Ther 14: 2228-2237, 2015. 
15. Lee CJ, Kim KW, Lee HM, Nahm FS, Lim YJ, Park JH and Kim CS: The effect of thalidomide on spinal cord ischemia/reperfusion injury in a rabbit model. Spinal Cord 45: 149-157, 2007.

16. Muller GW, Corral LG, Shire MG, Wang H, Moreira A, Kaplan G and Stirling DI: Structural modifications of thalidomide produce analogs with enhanced tumor necrosis factor inhibitory activity. J Med Chem 39: 3238-3240, 1996.

17. Muller GW, Chen R, Huang SY, Corral LG, Wong LM, PattersonRT, Chen Y,Kaplan Gand Stirling DI: Amino-substituted thalidomide analogs: Potent inhibitors of TNF-alpha production. Bioorg Med Chem Lett 9: 1625-1630, 1999.

18. Leask A and Abraham DJ: TGF-beta signaling and the fibrotic response. FASEB J 18: 816-827, 2004.

19. Javelaud D and Mauviel A: Crosstalk mechanisms between the mitogen-activated protein kinase pathways and Smad signaling downstream of TGF-beta: Implications for carcinogenesis. Oncogene 24: 5742-5750, 2005.

20. Zhang YE: Non-Smad pathways in TGF-beta signaling. Cell Res 19: 128-139, 2009.

21. Choe JY, Jung HJ, Park KY, Kum YS, Song GG, Hyun DS, Park SH and Kim SK: Anti-fibrotic effect of thalidomide through inhibiting TGF-beta-induced ERK1/2 pathways in bleomycin-induced lung fibrosis in mice. Inflamm Res 59: 177-188, 2010.

22. Liang CJ, Yen YH, Hung LY, Wang SH, Pu CM, Chien HF, Tsai JS, Lee CW, Yen FL and Chen YL: Thalidomide inhibits fibronectin production in TGF- $\beta 1$-treated normal and keloid fibroblasts via inhibition of the p38/Smad3 pathway. Biochem Pharmacol 85: 1594-1602, 2013.

23. George A, Marziniak M, Schäfers M, Toyka KV and Sommer C: Thalidomide treatment in chronic constrictive neuropathy decreases endoneurial tumor necrosis factor-alpha, increases interleukin-10 and has long-term effects on spinal cord dorsal horn met-enkephalin. Pain 88: 267-275, 2000.

24. Shannon E, Noveck R, Sandoval F and Kamath B: Thalidomide suppressed IL-1beta while enhancing TNF-alpha and IL-10, when cells in whole blood were stimulated with lipopolysaccharide. Immunopharmacol Immunotoxicol 30: 447-457, 2008.

25. Li S, Pal R, Monaghan SA, Schafer P, Ouyang H, Mapara M, Galson DL and Lentzsch S: IMiD immunomodulatory compounds block C/EBP-beta translation through eIF4E down-regulation resulting in inhibition of MM. Blood 117: 5157-5165, 2011.

26. Li H, Yoon JH, Won HJ, Ji HS, Yuk HJ, Park KH, Park HY and Jeong TS: Isotrifoliol inhibits pro-inflammatory mediators by suppression of TLR/NF- $\mathrm{BB}$ and TLR/MAPK signaling in LPS-induced RAW264.7 cells. Int Immunopharmacol: 110-119, 2017.

27. Lai CS, Lee JH, Ho CT, Liu CB, Wang JM, Wang YJ and Pan MH: Rosmanol potently inhibits lipopolysaccharide-induced iNOS and COX-2 expression through downregulating MAPK, NF-kappaB, STAT3 and C/EBP signaling pathways. J Agric Food Chem 57: 10990-10998, 2009.

28. Hoang B, Zhu L, Shi Y, Frost P, Yan H, Sharma S, Sharma S, Goodglick L, Dubinett S and Lichtenstein A: Oncogenic RAS mutations in myeloma cells selectively induce cox-2 expression, which participates in enhanced adhesion to fibronectin and chemoresistance. Blood 107: 4484-4490, 2006.

29. Prince HM, Mileshkin L, Roberts A, Ganju V, Underhill C Catalano J, Bell R, Seymour JF, Westerman D, Simmons PJ, et al: A multicenter phase II trial of thalidomide and celecoxib for patients with relapsed and refractory multiple myeloma. Clin Cancer Res 11: 5504-5514, 2005.

30. Knight R: IMiDs: A novel class of immunomodulators. Semin Oncol 32 (4 Suppl 5): S24-S30, 2005.

31. Teo SK: Properties of thalidomide and its analogues: Implications for anticancer therapy. AAPS J 7: E14-E19, 2005.

32. Galustian C, Meyer B, Labarthe MC, Dredge K, Klaschka D, Henry J, Todryk S, Chen R, Muller G, Stirling D, et al: The anti-cancer agents lenalidomide and pomalidomide inhibit the proliferation and function of T regulatory cells. Cancer Immunol Immunother 58: 1033-1045, 2009.

33. Luptakova K, Rosenblatt J, Glotzbecker B, Mills H, Stroopinsky D, Kufe T, Vasir B, Arnason J, Tzachanis D, Zwicker JI, et al: Lenalidomide enhances anti-myeloma cellular immunity. Cancer Immunol Immunother 62: 39-49, 2013.

34. Altman A and Villalba M: Protein kinase C-theta (PKC theta): A key enzyme in T cell life and death. J Biochem 132: 841-846, 2002 .
35. Payvandi F, Wu L, Naziruddin SD, Haley M, Parton A, Schafer PH, Chen RS, Muller GW, Hughes CC and Stirling DI: Immunomodulatory drugs (IMiDs) increase the production of IL-2 from stimulated T cells by increasing PKC-theta activation and enhancing the DNA-binding activity of AP-1 but not NF-kappaB, OCT-1, or NF-AT. J Interferon Cytokine Res 25: 604-616, 2005

36. Kim BS, Kim JY, Lee JG, Cho Y, Huh KH, Kim MS and Kim YS: Immune modulatory effect of thalidomide on T cells. Transplant Proc 47:787-790, 2015.

37. Gandhi AK, Kang J, Havens CG, Conklin T, Ning Y, Wu L, Ito T, Ando H, Waldman MF, Thakurta A, et al: Immunomodulatory agents lenalidomide and pomalidomide co-stimulate $\mathrm{T}$ cells by inducing degradation of T cell repressors Ikaros and Aiolos via modulation of the E3 ubiquitin ligase complex CRL4(CRBN). Br J Haematol1 64: 811-821, 2014.

38. Zhu D, Corral LG, Fleming YW and Stein B: Immunomodulatory drugs Revlimid (lenalidomide) and CC-4047 induce apoptosis of both hematological and solid tumor cells through NK cell activation. Cancer Immunol Immunother 57: 1849-1859, 2008.

39. Wu L, Adams M, Carter T, Chen R, Muller G, Stirling D, Schafer P and Bartlett JB: lenalidomide enhances natural killer cell and monocyte-mediated antibody-dependent cellular cytotoxicity of rituximab-treated CD20+ tumor cells. Clin Cancer Res 14: 4650-4657, 2008

40. Yaccoby S, Johnson CL, Mahaffey SC, Wezeman MJ, Barlogie B, Epstein J: Antimyeloma efficacy of thalidomide in the SCID-hu model. Blood 100: 4162-4168, 2002.

41. Lv P, Luo HS, Zhou XP, Xiao YJ, Paul SC, Si XM and Zhou YH: Reversal effect of thalidomide on established hepatic cirrhosis in rats via inhibition of nuclear factor-kappaB/inhibitor of nuclear factor-kappaB pathway. Arch Med Res 38: 15-27, 2007.

42. Lebrin F, Srun S, Raymond K, Martin S, van den Brink S, Freitas C, Bréant C, Mathivet T, Larrivée B, Thomas JL, et al: Thalidomide stimulates vessel maturation and reduces epistaxis in individuals with hereditary hemorrhagic telangiectasia. Nat Med 16: 420-428, 2010

43. Gupta D, Treon SP, Shima Y, Hideshima T, Podar K, Tai YT, Lin B, Lentzsch S, Davies FE, Chauhan D, et al: Adherence of multiple myeloma cells to bone marrow stromal cells upregulates vascular endothelial growth factor secretion: Therapeutic applications. Leukemia 15: 1950-1961, 2001.

44. Yabu T, Tomimoto H, Taguchi Y, Yamaoka S, Igarashi Y and Okazaki T: Thalidomide-induced antiangiogenic action is mediated by ceramide through depletion of VEGF receptors and is antagonized by sphingosine-1-phosphate. Blood 106: 125-134, 2005 .

45. Dredge K, Horsfall R, Robinson SP, Zhang LH, Lu L, Tang Y, Shirley MA, Muller G, Schafer P, Stirling D, et al: Orally administered lenalidomide (CC-5013) is anti-angiogenic in vivo and inhibits endothelial cell migration and Akt phosphorylation in vitro. Microvasc Res 69: 56-63, 2005.

46. Komorowski J, Jerczyńska H, Siejka A, Barańska P, Ławnicka H, Pawłowska Z and Stepien H: Effect of thalidomide affecting VEGF secretion, cell migration, adhesion and capillary tube formation of human endothelial EA. hy 926 cells. Life sciences 78: 2558-2563, 2006.

47. Jinnin M: Mechanisms of skin fibrosis in systemic sclerosis. J Dermatol 37: 11-25, 2010.

48. Oliver SJ, Moreira A and Kaplan G: Immune stimulation in scleroderma patients treated with thalidomide. Clin Immunol 97: 109-120, 2000

49. Weingärtner S, Zerr P, Tomcik M, Palumbo-Zerr K, Distler A, Dees C, Beyer C, Shankar SL, Cedzik D, Schafer PH, et al: Pomalidomide is effective for prevention and treatment of experimental skin fibrosis. Ann Rheum Dis 71: 1895-1899, 2012.

50. Ingen-Housz-Oro S, Ortonne N, Elhai M, Allanore Y, Aucouturier P and Chosidow O: IgG4-related skin disease successfully treated by thalidomide: A report of 2 cases with emphasis on pathological aspects. JAMA Dermatol 149: 742-187, 2013.

51. Selman M, King TE and Pardo A, American Thoracic Society; European Respiratory Society; American College of Chest Physicians: Idiopathic pulmonary fibrosis: Prevailing and evolving hypotheses about its pathogenesis and implications for therapy. Ann Intern Med 134: 136-151, 2001.

52. SHI Jie, Qiang N-X and YU Min: Clinical research and correlated cytokine study of thalidomide combined with prednisone on idiopathic pulmonary fibrosis. Practical Pharmacy and Clinical Remedies 10: 5, 2012. 
53. Zhang L and Yang WL: Effect of thalidomide on the expressions of IL-6, TNF- $\alpha$ and TGF- $\beta 1$ in BALF of elder patients with idiopathic pulmonary fibrosis. Journal of Xian Jiaotong University (Medical Sciences) 5: 622-625, 2012.

54. Tabata C, Tabata R, Kadokawa Y, Hisamori S, Takahashi M, Mishima M, Nakano T and Kubo H: Thalidomide prevents bleomycin-induced pulmonary fibrosis in mice. J Immunol 179: 708-714, 2007.

55. Knobloch J, Jungck D and Koch A: Apoptosis induction by thalidomide: Critical for limb teratogenicity but therapeutic potential in idiopathic pulmonary fibrosis? Curr Mol Pharmacol 4: 26-61, 2011.

56. Horton MR, Santopietro V, Mathew L, Horton KM, Polito AJ, Liu MC, Danoff SK and Lechtzin N: Thalidomide for the treatment of cough in idiopathic pulmonary fibrosis: A randomized trial. Ann Intern Med 157: 398-406, 2012.

57. Rethinking thalidomide: Environ Health Perspect 103: 132, 1995.

58. Mall JW, Schwenk W, Philipp AW, Büttemeyer R and Pollmann C: Intraperitoneal administration of the angiogenesis inhibitor thalidomide does not impair anastomotic healing following large bowel resection in a rabbit model. World J Surg 27: 1119-1123, 2003.

59. Kruse FE, Joussen AM, Rohrschneider K, Becker MD and Völcker HE: Thalidomide inhibits corneal angiogenesis induced by vascular endothelial growth factor. Graefes Arch Clin Exp Ophthalmol 236: 461-466, 1998.

60. Ribeiro JC, Vagnaldo Fechine F, Ribeiro MZ, Barreiro EJ, Lima LM, Ricardo NM, Amaral de Moraes ME and Odorico de Moraes M: Potential inhibitory effect of LASSBio-596, a new thalidomide hybrid, on inflammatory corneal angiogenesis in rabbits. Ophthalmic Res 48: 177-185, 2012.

61. Abbas A, Khan B, Feroze AH and Hyman GF: Thalidomide prevents donor corneal graft neovascularization in an alkali burn model of corneal angiogenesis. J Pak Med Assoc 52: 476-482, 2002.

62. Lee YK and Chung SK: The inhibitory effect of thalidomide analogue on corneal neovascularization in rabbits. Cornea 32 $1142-1148,2013$

63. Srinivasan S, Perez-Gomez I, O'Donnell C and Batterbury M: Corneal endothelial abnormalities associated with thalidomide toxicity. Cornea 24: 103-105, 2005.

64. Huang YH and Tseng SH: Corneal snowflakes. Lancet 380: 506 , 2012.

65. Guex-Crosier Y, Pittet N and Herbort CP: The effect of thalidomide and supidimide on endotoxin-induced uveitis in rats. Graefes Arch Clin Exp Ophthalmol 233: 90-93, 1995.

66. Rodrigues GB, Passos GF, Di Giunta G, Figueiredo CP Rodrigues EB, Grumman A Jr, Medeiros R and Calixto JB Preventive and therapeutic anti-inflammatory effects of systemic and topical thalidomide on endotoxin-induced uveitis in rats. Exp Eye Res 84: 553-560, 2007.

67. Parentin F, Da Pozzo S, Lepore L and Perissutti P: Thalidomide effectiveness for bilateral chronic idiopathic anterior uveitis in a three-year-old child. Ophthalmologica 215: 70-73, 2001.

68. Ip M and Gorin MB: Recurrence of a choroidal neovascular membrane in a patient with punctate inner choroidopathy treated with daily doses of thalidomide. Am J Ophthalmol 122: 594-595, 1996.
69. Rabinowitz R, Katz G, Rosner M, Pri-Chen S and Spierer A: The effect of thalidomide on neovascularization in a mouse model of retinopathy of prematurity. Graefes Arch Clin Exp Ophthalmol 246: 843-848, 2008

70. Verma AS and Fitzpatrick DR: Anophthalmia and microphthalmia. Orphanet J Rare Dis 2: 47, 2007.

71. Ema M, Ise R, Kato H, Oneda S, Hirose A, Hirata-Koizumi M, Singh AV, Knudsen TB and Ihara T: Fetal malformations and early embryonic gene expression response in cynomolgus monkeys maternally exposed to thalidomide. Reprod Toxicol 29: 49-56, 2010.

72. Christian MS, Laskin OL, Sharper V, Hoberman A, Stirling DI and Latriano L: Evaluation of the developmental toxicity of lenalidomide in rabbits. Birth Defects Res B Dev Reprod Toxicol 80: 188-207, 2007.

73. Zeldis JB, Carter TL, Knight RD and Hui J: Pomalidomide is teratogenic in rats and rabbits and can be neurotoxic in humans. Proc Natl Acad Sci USA 110: E4819, 2013.

74. Narita N, Kato M, Tazoe M, Miyazaki K, Narita M and Okado N: Increased monoamine concentration in the brain and blood of fetal thalidomide- and valproic acid-exposed rat: Putative animal models for autism. Pediatr Res 52: 576-579, 2002.

75. Elkinson S and McCormack PL: Pomalidomide: First global approval. Drugs 73: 595-604, 2013.

76. Lacy MQ: New immunomodulatory drugs in myeloma. Curr Hematol Malig Rep 6: 120-125, 2011.

77. Streetly MJ, Gyertson K, Daniel Y, Zeldis JB, Kazmi M and Schey SA: Alternate day pomalidomide retains anti-myeloma effect with reduced adverse events and evidence of in vivo immunomodulation. Br J Haematol 141: 41-51, 2008.

78. Lacy MQ, Kumar SK, LaPlant BR, Laumann K, Gertz MA, Hayman SR, Buadi FK, Dispenzieri A, Lust JA, Russell R, et al: Pomalidomide plus low-dose dexamethasone (Pom/Dex) in relapsed myeloma: Long term follow up and factors predicing outcome in 345 patients. Blood 120: 201, 2012.

79. Daver N, Shastri A, Kadia T, Newberry K, Pemmaraju N, Jabbour E, Zhou L, Pierce S, Cortes J, Kantarjian H and Verstovsek S: Phase II study of pomalidomide in combination with prednisone in patients with myelofibrosis and significant anemia. Leuk Res 38: 1126-1129, 2014.

80. Weber DM, Chen C, Niesvizky R, Wang M, Belch A, Stadtmauer EA, Siegel D, Borrello I, Rajkumar SV, Chanan-Khan AA, et al: Lenalidomide plus dexamethasone for relapsed multiple myeloma in North America. N Engl J Med 357: 2133-2142, 2007.

81. Dimopoulos M, Spencer A, Attal M, Prince HM, Harousseau JL, Dmoszynska A, San Miguel J, Hellmann A, Facon T, Foà R, et al:Lenalidomide plus dexamethasone for relapsed or refractory multiple myeloma. N Engl J Med 357: 2123-2132, 2007.

82. Chen C, Reece DE, Siegel D, Niesvizky R, Boccia RV, Stadtmauer EA, Abonour R, Richardson P, Matous J, Kumar S, et al: Expanded safety experience with lenalidomide plus dexamethasone in relapsed or refractory multiple myeloma. Br J Haematol 146: 164-170, 2009. 